\title{
Enhanced transport across entire length of plasma sheet boundary field lines leading to substorm onset
}

\author{
L. R. Lyons, ${ }^{1}$ Y. Nishimura, ${ }^{1,2}$ X. Xing, ${ }^{1}$ V. Angelopoulos, ${ }^{3}$ S. Zou, ${ }^{4}$ D. Larson, ${ }^{5}$ \\ J. McFadden, ${ }^{5}$ A. Runov, ${ }^{3}$ S. Mende, ${ }^{5}$ and K.-H. Fornacon ${ }^{6}$ \\ Received 16 June 2010; revised 23 August 2010; accepted 25 August 2010; published 24 November 2010.
}

[1] Recently, images from the THEMIS all-sky imager array were used to suggest that longitudinally localized enhanced plasma transport across the nightside open-closed boundary (separatrix) 5.5 min before substorm onset leads to intrusion of new plasma toward the near-Earth plasma sheet and to substorm onset via near-Earth instability. If such reconnection-related flow enhancements precede substorm onsets, they should be seen along the entire length of separatrix field lines within the appropriate longitudinal region as perpendicular flow before onset. Evidence for such flows has been previously reported for four events over a limited radial extent. Based on 13 substorm events with at least one of the THEMIS spacecraft near the outer boundary of the plasma sheet in the premidnight region and simultaneous auroral images, we find here that enhanced flows toward the plasma sheet center are often seen (11 of 13 events) in the premidnight sector a few minutes prior to onset from $X \sim-11$ to $-26 \mathrm{R}_{\mathrm{E}}$. Previous radar observations within the ionosphere have also shown that such enhanced flows bringing new plasma into the auroral zone from polar cap field lines prior to onset are common. Assuming that the outer boundary of the plasma sheet approximately demarcates the open-closed field line boundary, these results indicate that reconnection-related flow enhancements do indeed precede substorm onset along the entire radial extent of the plasma sheet outer boundary. Consistent with longitudinal localization, enhanced flows toward the plasma sheet center were not observed on all spacecraft for five events where there were more than one spacecraft near the plasma sheet boundary.

Citation: Lyons, L. R., Y. Nishimura, X. Xing, V. Angelopoulos, S. Zou, D. Larson, J. McFadden, A. Runov, S. Mende, and K.-H. Fornacon (2010), Enhanced transport across entire length of plasma sheet boundary field lines leading to substorm onset, J. Geophys. Res., 115, A00I07, doi:10.1029/2010JA015831.

\section{Introduction}

[2] Observations from the all-sky imager (ASI) array [Mende et al., 2008] of the THEMIS program [Sibeck and Angelopoulos, 2008] have been recently used to suggest a possible resolution to the long-standing problem of determining the sequence of events leading to substorm onset [Nishimura et al., 2010]. In particular, a repeatable auroral sequence was often observed. The sequence starts with

\footnotetext{
${ }^{1}$ Department of Atmospheric and Oceanic Sciences, University of California, Los Angeles, California, USA.

${ }^{2}$ Solar-Terrestrial Environment Laboratory, Nagoya University, Nagoya, Aichi, Japan.

${ }^{3}$ Department of Earth and Space Sciences, University of California, Los Angeles, California, USA.

${ }^{4}$ Department of Atmospheric, Oceanic and Space Sciences, University of Michigan, Ann Arbor, Michigan, USA.

${ }^{5}$ Space Sciences Laboratory, University of California, Berkeley, California, USA.

${ }^{6}$ Institut für Geophysik und Extraterrestrische Physik, Technische Universität Braunschweig, Braunschweig, Germany.

Copyright 2010 by the American Geophysical Union. 0148-0227/10/2010JA015831
}

formation of a poleward boundary intensification (PBI) near the auroral poleward boundary, which lies approximately along the boundary between open and closed magnetic field lines, or magnetic separatrix. A roughly north-south oriented $(\mathrm{N}-\mathrm{S})$ auroral form then extends equatorward from the PBI toward the equatorward boundary of the aurora oval. Auroral onset occurs either near the location where the N-S auroral form first reaches a growth phase arc located near the equatorward boundary of the auroral oval or after an enhanced auroral luminosity region moves azimuthally along the equatorial arc to the onset location. The average time between PBI intensification and substorm onset was found by Nishimura et al. to be $5.5 \mathrm{~min}$.

[3] Based on the known relation between auroral enhancements and plasma sheet flows [e.g., de la Beaujardière et al., 1994; Lyons et al., 1999; Sergeev et al., 1999, 2000; Nakamura et al., 2001; Zesta et al., 2002; Henderson et al., 2002], Nishimura et al. [2010] suggested that new plasma crosses the polar cap boundary into the plasma sheet over a longitudinally localized region and then intrudes to the nearEarth region of the plasma sheet, leading to onset. Such enhanced transport across the magnetic separatrix corresponds 

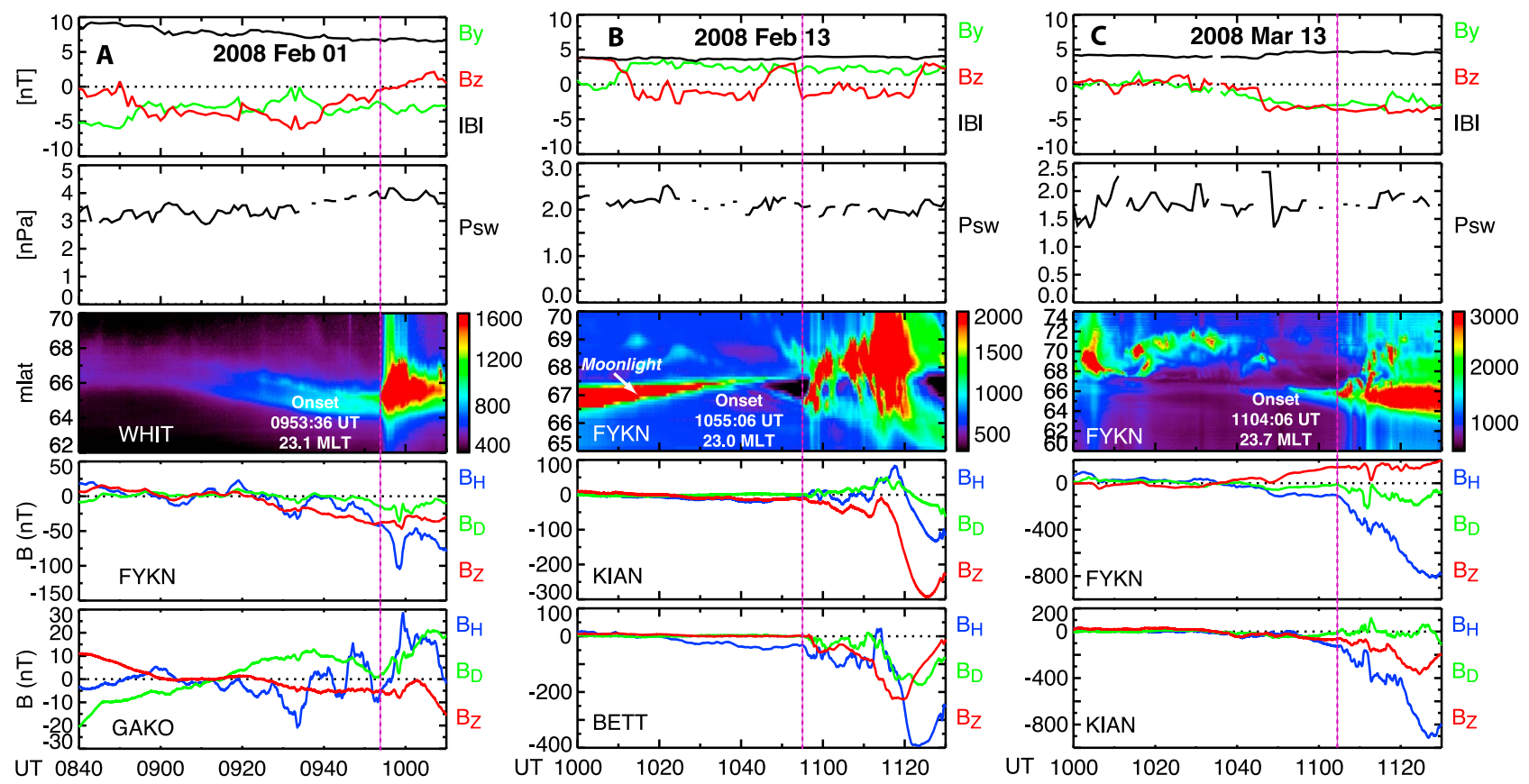

Figure 1. (a) The 1 February 2008 substorm. (b) The 13 February 2008 substorm. (c) The 13 March 2008 substorm. (top two rows) The IMF and solar wind dynamic pressure shifted to the bow shock nose. (middle row) The auroral intensity as a function of invariant latitude and UT along a magnetic meridian near the auroral onset meridian. (bottom two rows) Magnetometer data from two stations near the onsets. Vertical lines mark the onset times.

to an increase in the local reconnection rate [de la Beaujardière et al., 1991; Blanchard et al., 1996]. Under the assumption of equipotential field lines, the enhanced flow across the separatrix should extend along the entire length of the separatrix from the ionosphere to the $\mathrm{X}$ line within the longitude range of the enhanced reconnection [Vasyliunas, 1984; Blanchard et al., 1996].

[4] Consistent with the expectation of enhanced flow across the separatrix, Angelopoulos et al. [2008, 2009] reported enhanced flows toward the center of the plasma sheet $\sim 1-2$ min prior to onset for four substorm events. The flows were measured by the THEMIS spacecraft located at $\mathrm{X}=-17$ to $-22 \mathrm{R}_{\mathrm{E}}$ in the premidnight region of the magnetotail, and the enhanced flows were interpreted as a signature of enhanced reconnection preceding substorm onset. The times of flow enhancements were prior to the onset but the PBI intensifications reported by Nishimura et al. [2010] were even earlier. However, the THEMIS spacecraft were still within the plasma sheet at the time of the onsets, and there should be some time delay between when the flows first crossed the open-closed field line boundary and when they reached the spacecraft. Furthermore, a spacecraft would need to be located at the right longitude to detect the earliest flow, since longitudinal propagation would generally be needed for the enhanced flow region to extend from its initial longitude to the spacecraft location.

[5] Consistent with the expectation of enhanced flows across the entire length of the separatrix field lines, Lyons et al. [2010] examined Sondrestrom incoherent scatter radar observations and found that enhanced ionospheric flows commonly enter the plasma sheet from the polar cap an average of $\sim 8 \mathrm{~min}$ prior to onset. The radar measurements cover several degrees of latitude, so that the time the flows first cross the open-closed field line boundary is determined more accurately with the radar than with the spacecraft. Here we use THEMIS spacecraft observations to determine if the preonset flow signature found by Angelopoulos et al. [2008, 2009] is seen at various distances from the Earth near the outer boundary of the plasma sheet. Simultaneous ASI observations, which detect PBI timing and location and the following time sequence leading to onset, are available for all events in this study.

\section{Observations}

[6] A total of 13 substorm events were identified for this study having clear auroral onsets in the THEMIS ASI array and for which at least one of the THEMIS spacecraft was located near the outer boundary of the plasma sheet in the premidnight region. There are a total of 22 THEMIS spacecraft observations in the appropriate region during these 13 events. Figure 1 shows the auroral intensity as a function of invariant latitude and UT along a magnetic meridian near the auroral onset meridian for three of these events. The interplanetary magnetic field (IMF) and solar wind dynamic pressure shifted to the bow shock nose, obtained from http://omniweb.gsfc.nasa.gov/form/sc_merge min 1.html, are shown in Figure 1 (top two rows), and magnetometer data from two stations near each of the onsets are shown in Figure 1 (bottom two rows). We first show observations from the three events shown in Figure 1 and then summarize the results from all the events. 


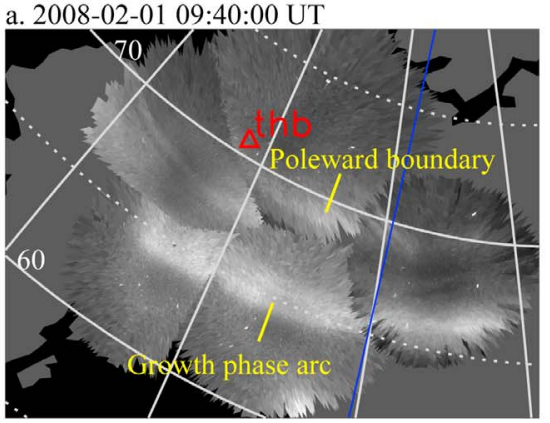

b. $2008-02-0109 \cdot 43 \cdot 42$ UT

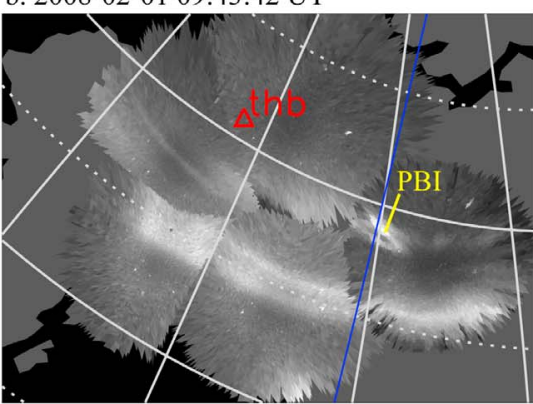

e. 2008-02-01 09:54:12 UT
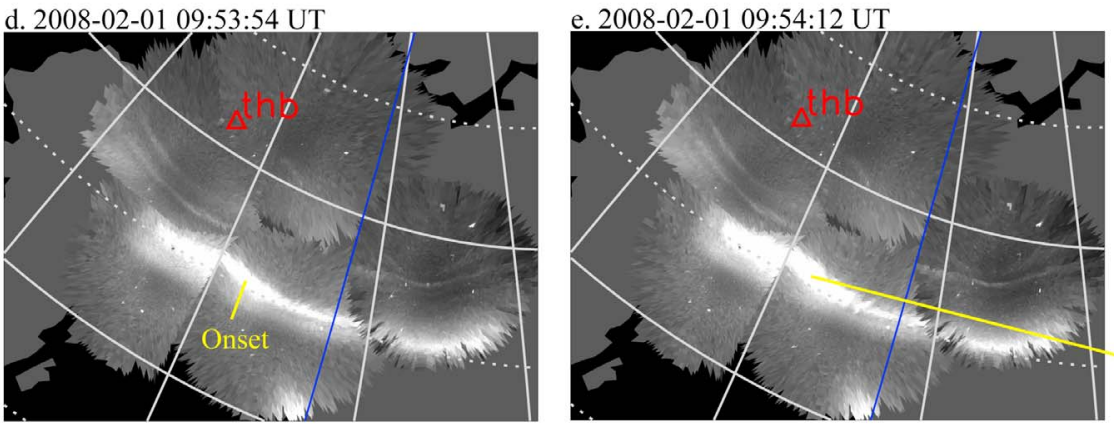

c. $2008-02-0109: 47: 18$ UT

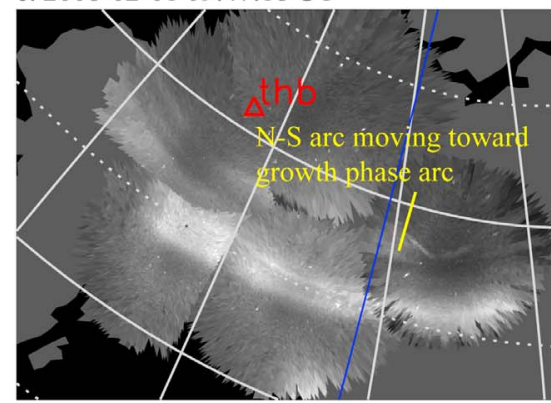

f. 2008-02-01 09:59:00 UT

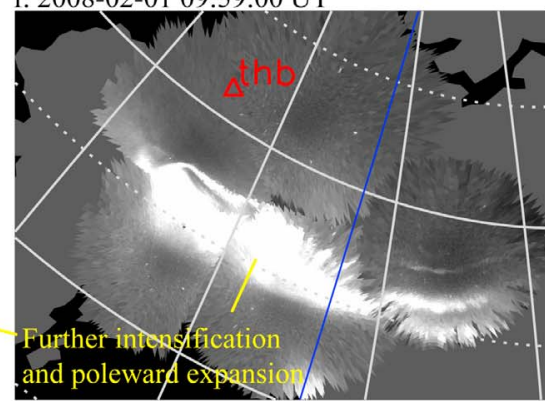

Figure 2. White light images from five ASI stations covering Alaska and western Canada for times selected to show a substorm with onset first detected at 0953:36 UT on 1 February 2008. White solid lines give every $10^{\circ}$ in latitude and $1 \mathrm{~h}$ in longitude. Blue line identifies the magnetic midnight meridian. The mapping of the THEMIS B spacecraft (THB) field line was obtained as described in the text.

\subsection{The 1 February 2008 Event}

[7] Figure 2 shows white light images from five ASI stations covering Alaska and western Canada for times selected to show a substorm with onset first detected at 0953:36 UT on 1 February 2008. A blue line is drawn approximately along the magnetic midnight meridian. The preonset auroral sequence found by Nishimura et al. [2010] is also identified in this event. The first image shows the auroral poleward boundary at invariant latitude $\Lambda \sim 69^{\circ}$ and a band of diffuse appearing auroral emissions at the auroral equatorward boundary that is centered at $\Lambda \sim 65^{\circ}$ and labeled "growth phase arc." A PBI is first seen in the second image, this arc being followed by a weak arc (labeled N-S arc) that continued equatorward until reaching the growth phase arc, leading to onset along the poleward portion of the growth phase arc.

[8] The auroral intensity as a function of latitude and time along a magnetic meridian (within the western portion of the field of view at the ASI station WHIT) that is near the first detectable auroral brightening of the 1 February 2008 substorm is shown in Figure 1a (middle row). This meridian was at 23.1 MLT at the time of onset, and the development and equatorward motion of the growth phase arc, as well as onset along the poleward boundary of that arc, can clearly be seen. Modest onset signatures can be seen in the ground magnetometer data from the two stations slightly to the west of the onset shown in Figure 1a (bottom two rows). FYKN, located somewhat poleward of the onset latitude shows a small negative $B_{x}$ perturbation and GAKO, somewhat equatorward of the onset, shows a small positive $B_{x}$ perturbation. This is as expected from the westward (eastward) electrojet enhancement that develops poleward (equatorward) of the auroral onset latitude [Zou et al., 2009].

[9] The THEMIS B spacecraft (THB) was located near the outer boundary of the premidnight plasma sheet during this event at $X \sim-26 R_{E}$. To get an idea of where the spacecraft mapped to within the auroral oval, we used the Tsyganenko 1996 (T96) magnetic field model [Tsyganenko, 1995] with full IGRF representation of the Earth's internal magnetic field. For this event, the model had THB on open, Southern Hemisphere field lines, so we mapped the spacecraft to the southern polar cap and then switched the sign of the magnetic latitude to project onto the northern hemisphere images in Figure 2. This mapping is very uncertain, and the T01 and T04 models map THB 1-2 $\mathrm{h}$ further to the east than does T96. Also the IMF $\mathrm{B}_{\mathrm{y}}$ was negative during this period. Thus, assuming the spacecraft was on closed field lines, a partial penetration of $\mathrm{B}_{\mathrm{y}}$ into the magnetosphere as found by Cowley and Hughes [1983] should move the mapping of the spacecraft further to the east in the northern hemisphere.

[10] Figure 3 shows observations from THB. Figure 3 (top two rows) shows energy flux spectrograms for ions (i) and electrons (e) from the electrostatic analyzer (ESA) [McFadden et al., 2008] and solid-state detector (SST). Figure 3 (bottom five rows, from top to bottom) shows the pressure (total $\mathrm{P}_{\text {tot }}$, thermal $\mathrm{P}_{\text {th }}$, and magnetic $\mathrm{P}_{\text {mag }}$ from the Themis magnetometer [Auster et al., 2008]), the components of the magnetic field $\left(\mathrm{B}_{\mathrm{x}}, \mathrm{B}_{\mathrm{y}}, \mathrm{B}_{\mathrm{z}}\right)$, the components of the perpendicular velocity moment $\mathbf{V}_{\text {perp }}$, the components of the electric drift velocity $\mathbf{V}_{\mathrm{E} \times \mathrm{B}}$ obtained from the measured electric and magnetic fields, and the plasma density N. As 


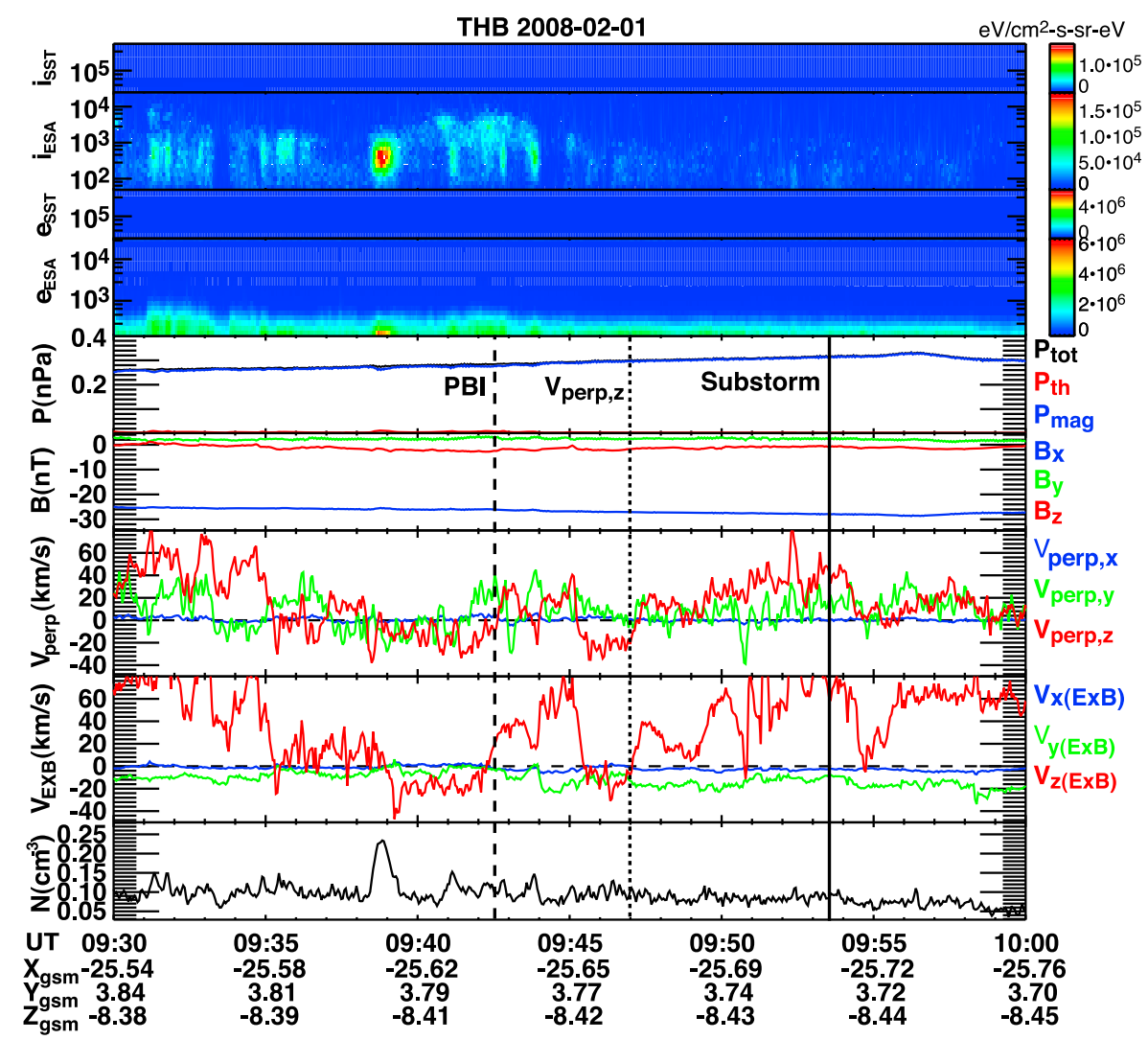

Figure 3. Observations from THB during the period of the substorm on 1 February 2008. The times of first detection of the PBI leading to onset, of the persistent $V_{\text {perp, }}$ prior to onset, and of the onset are indicated. (top two rows) Energy flux spectrograms for ions (i) and electrons (e) from the electrostatic analyzer (ESA) and solid-state detector (SST). (bottom five rows, from top to bottom) The pressure (total $\mathrm{P}_{\text {tot }}$, thermal $\mathrm{P}_{\text {th }}$, and magnetic $\mathrm{P}_{\mathrm{mag}}$ ), the components of the perpendicular velocity moment $\mathrm{V}_{\text {perp }}$, the components of the electric drift velocity $\mathrm{V}_{\mathrm{E} \times \mathrm{B}}$ obtained from the measured electric and magnetic fields, and the plasma density. $\mathrm{V}_{\text {perp }}$ was calculated using both the ESA and SST.

seen from the measureable, but very low, ion energy fluxes in the spectrogram and the very low $P_{\text {th }}$ values relative $P_{\text {mag, }}$, the spacecraft was very near the outer boundary of the plasma sheet, making this example ideal for looking for enhanced flows near the open-closed field line boundary.

[11] The spacecraft was in the Southern Hemisphere and well away from the central plasma sheet, so that enhanced flow across the separatrix should appear as enhanced flow in the positive $\mathrm{z}$ direction. Just such a flow enhancement, persisting until the onset, is seen to have initiated $\sim 6.5 \mathrm{~min}$ prior to the onset. Because of the low plasma densities, we compare $V_{\text {perp, },}$ to the independently measured $V_{\mathrm{E} \times \mathrm{B}, \mathrm{z}}$. It can be seen that the temporal variations of $\mathrm{V}_{\text {perp, },}$ and of $\mathrm{V}_{\mathrm{E} \times \mathrm{B}, \mathrm{z}}$ are quite similar during the period in Figure 3 preceding the onset, and that their magnitudes generally agree to within an uncertainty of $\sim 20 \mathrm{~km} / \mathrm{s}$. This indicates that the measured values of $\mathrm{V}_{\text {perp,z }}$ are sufficiently accurate for determining the existence and approximate start times of flow enhancements. Since the magnetic field associated with the enhanced flow did not change, the enhanced flow is not likely to be related to the plasma sheet flapping but represents plasma inflow toward the center of the plasma sheet.

[12] The PBI preceding the substorm onset in Figure 2 initiated $\sim 4.5 \mathrm{~min}$ prior to the positive $\mathrm{V}_{\text {perp,z }}$ enhancement seen by THB, which is a likely result of longitudinal separation between the PBI and the spacecraft and the spacecraft being located an indeterminate distance equatorward of the open-closed field line boundary. Also, it is not possible to determine for sure that the observed flow enhancement was in fact an enhancement that was associated with the PBI that was observed to lead to onset. Unlike for the events discussed by Angelopoulos et al. [2008, 2009] and the events discussed below, there are other flow enhancements during the period shown in Figure 3 preceding the enhancement we have identified, as would be expected from the occurrence of multiple intensifications along the polar cap boundary during this period (not shown) that were not followed by detectable $\mathrm{N}-\mathrm{S}$ arcs. It is possible that the short flow burst observed at $\sim 0942-0945$ UT was related to an earlier PBI or to the PBI identified in Figure 2 (top middle) and the $\sim 1$ min gap between the two flow bursts resulted from flow burst structure. We can, however, conclude that enhanced perpendicular flow toward the center of the plasma sheet commenced several minutes before onset, consistent with the timings inferred by Nishimura et al. [2010] and with those observed within the ionosphere [Lyons et al., 2010], and that enhanced flow initiated in the premidnight region near the plasma sheet boundary at or before the $V_{\text {perp, } z}$ initiation time marked in Figure 2 (top middle). 

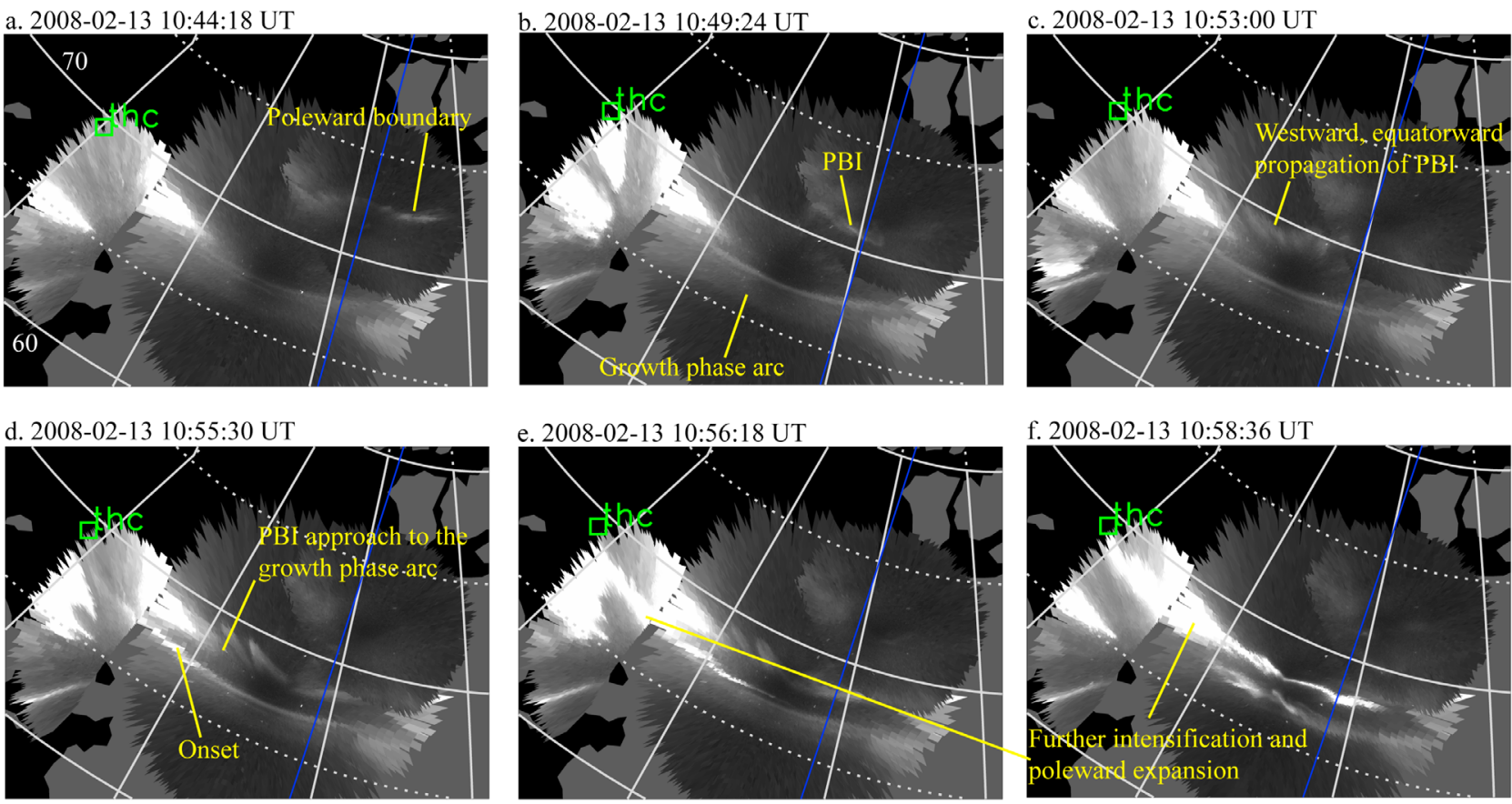

Figure 4. Same as Figure 2 except for white light images from ASI stations for a substorm over Alaska with onset first detected at 1055:06 UT on 13 February 2008.

\subsection{The 13 February 2008 Event}

[13] Figure 4 shows white light ASI images for a substorm over Alaska with auroral onset first detected at 1055:06 UT on 13 February 2008. The auroral poleward boundary and growth phase arc are identified as for the previous event. In this case, the broad diffuse growth phase arc has a narrow feature along the poleward edge. Because this feature is so narrow, it is likely an electron arc lying along the poleward edge of the diffuse growth phase arc. A faint PBI is first seen along the auroral poleward boundary at 1048:42 UT. In this case, the PBI moved westward, and the PBI and the polar cap boundary moved to within $\sim 2^{\circ}$ latitude poleward of the narrow growth phase arc. Moonlight prevents detection of any $\mathrm{N}-\mathrm{S}$ arc that may have moved to the onset location, but the onset itself is clearly seen just equatorward of the bright light of the moon near the PBI meridian.

[14] The auroral intensity as a function of latitude and time from the ASI at FYKN along a magnetic meridian very near the eastern edge of the moonlight and at 23.0 MLT at onset is shown in Figure 1b. The auroral onset can clearly be seen just equatorward of the moonlight (the narrow triangular shaped region of bright emissions before onset). Distinct magnetic signatures of onset can also be seen at the two magnetic stations shown in Figure $1 \mathrm{~b}$ that are near the onset latitude, KIAN, a little west of the onset longitude, and BETT, quite near the onset longitude. The IMF fluctuated from north to south during the period of the substorm. This is characteristic of the Alfvénic IMF fluctuations that occur during high-speed solar wind streams (the solar wind speed $\sim 650 \mathrm{~km} / \mathrm{s}$ ), and enhanced convection and substorms can be common whether the IMF is northward or southward during such periods [Kim et al., 2009; Lyons et al., 2009].

[15] During this event, the THEMIS C spacecraft (THC) was located near the outer boundary of the premidnight plasma sheet in the near-Earth region, $X \sim-12 R_{E}$. The mapping to the ionosphere shown in Figure 4 is along closed field lines from the Southern Hemisphere in the T96 model, which is subject to possibly substantial errors. As seen in Figure 5, the temporal variations of $\mathrm{V}_{\text {perp,z }}$ and $\mathrm{V}_{\mathrm{E} \times \mathrm{B}, \mathrm{z}}$ are again quite similar during the period preceding the onset, and their magnitudes generally agree to within $\sim 10 \mathrm{~km} / \mathrm{s}$, allowing us to estimate that the enhanced flow in the positive $\mathrm{z}$ direction, persisting until the onset, initiated $\sim 2.5 \mathrm{~min}$ prior to the onset at the spacecraft location in this case. The PBI identified with the substorm onset in Figure 4 initiated $\sim 3.5$ min prior to the positive $V_{\text {perp, }}$ enhancement seen by THC. It is again not possible to precisely determine if the observed flow enhancement was in fact an enhancement that was associated with the observed PBI near the spacecraft footprint. Nevertheless, since the PBI moved westward toward the spacecraft location after its formation and the longitudinal mapping and the distance from the separatrix are uncertain, the enhanced plasma flow toward the center of the plasma sheet is again consistent with the inferences of Nishimura et al. [2010]. For this event, the spacecraft location was much closer to the Earth than for the 1 February 2008 event, giving evidence in support of enhanced reconnection bringing plasma across the separatrix over its entire length of the appropriate field lines.

\subsection{The 13 March 2008 Event}

[16] ASI images for the third event (over Alaska, onset at 1104:24 UT on 13 March 2008), with the THB and THC spacecraft footprints, are shown in Figure 6. A faint PBI formed at $\sim 1057$ UT in the northern part of the INUV imager field of view. Light contamination makes it difficult to see the $\mathrm{N}-\mathrm{S}$ arc, which shows as a faint auroral form in Figure 6 (top middle) connecting the PBI to the onset region, but the onset can be seen in the ASI images and in 


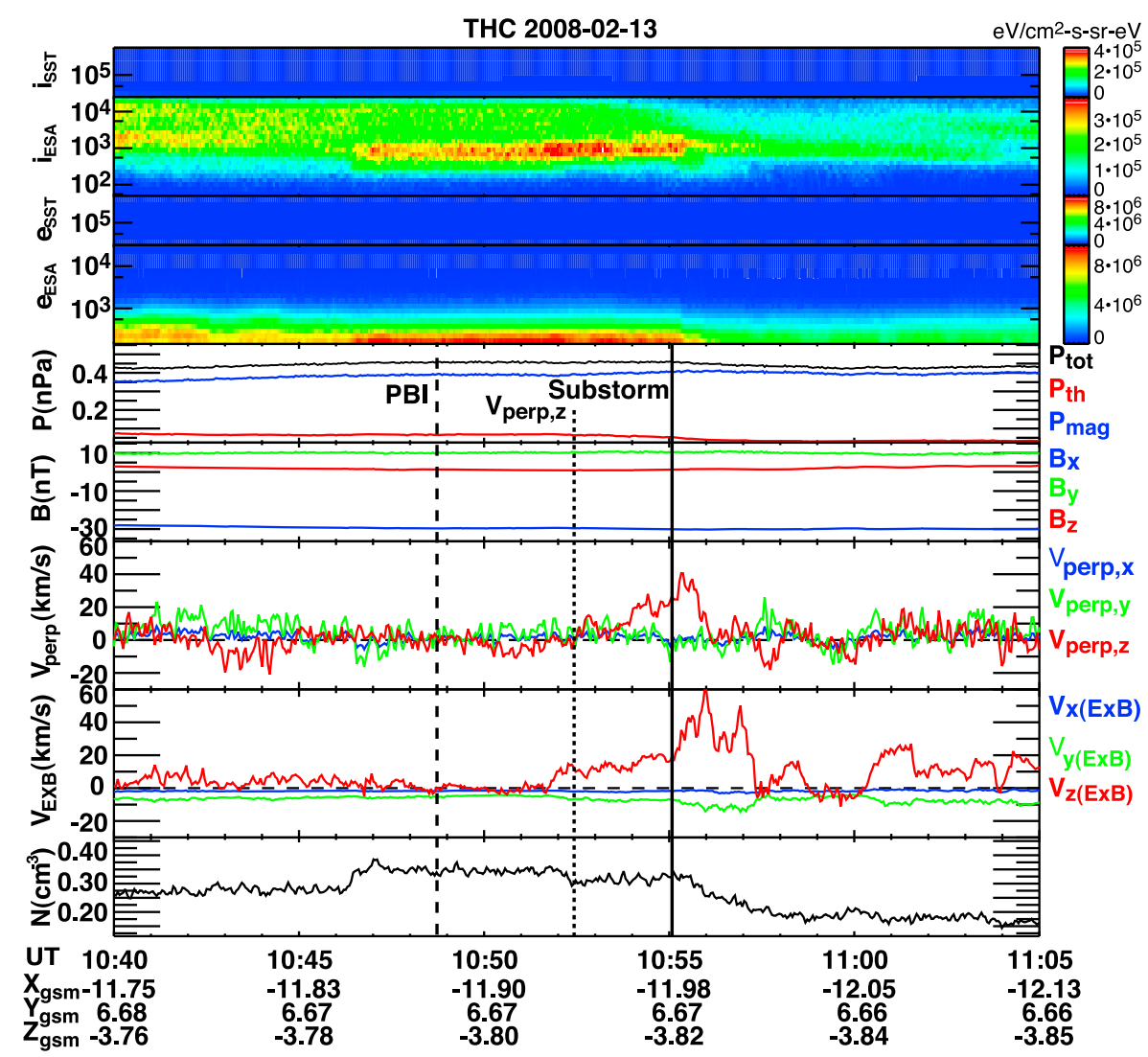

Figure 5. Same as Figure 3 except for observations from THEMIS C spacecraft (THC) during the period of the substorm on 13 February 2008.
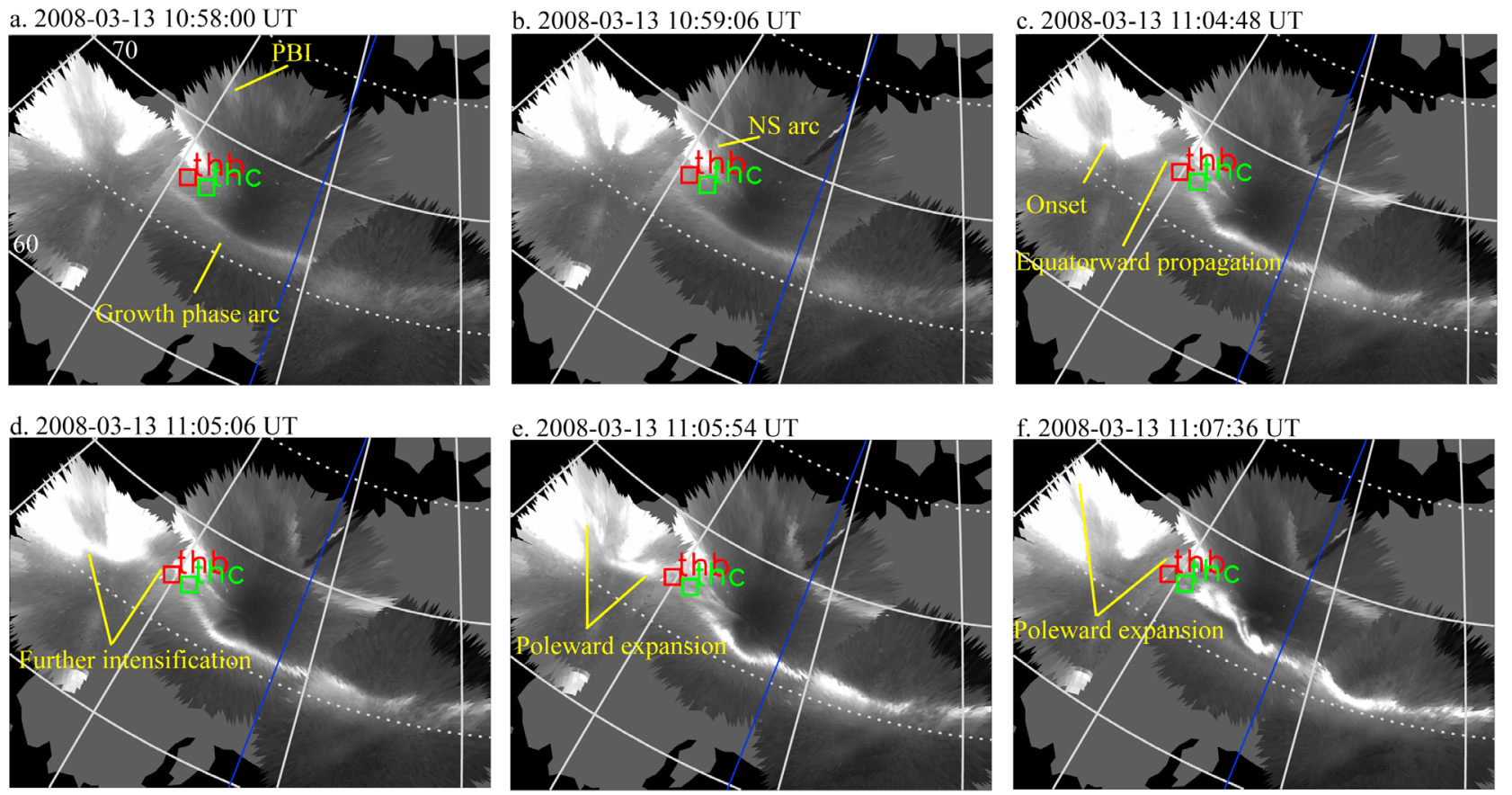

Figure 6. Same as Figure 2 except for white light images from ASI stations for a substorm over Alaska with onset first detected at 1104:24 UT on 13 March 2008. 


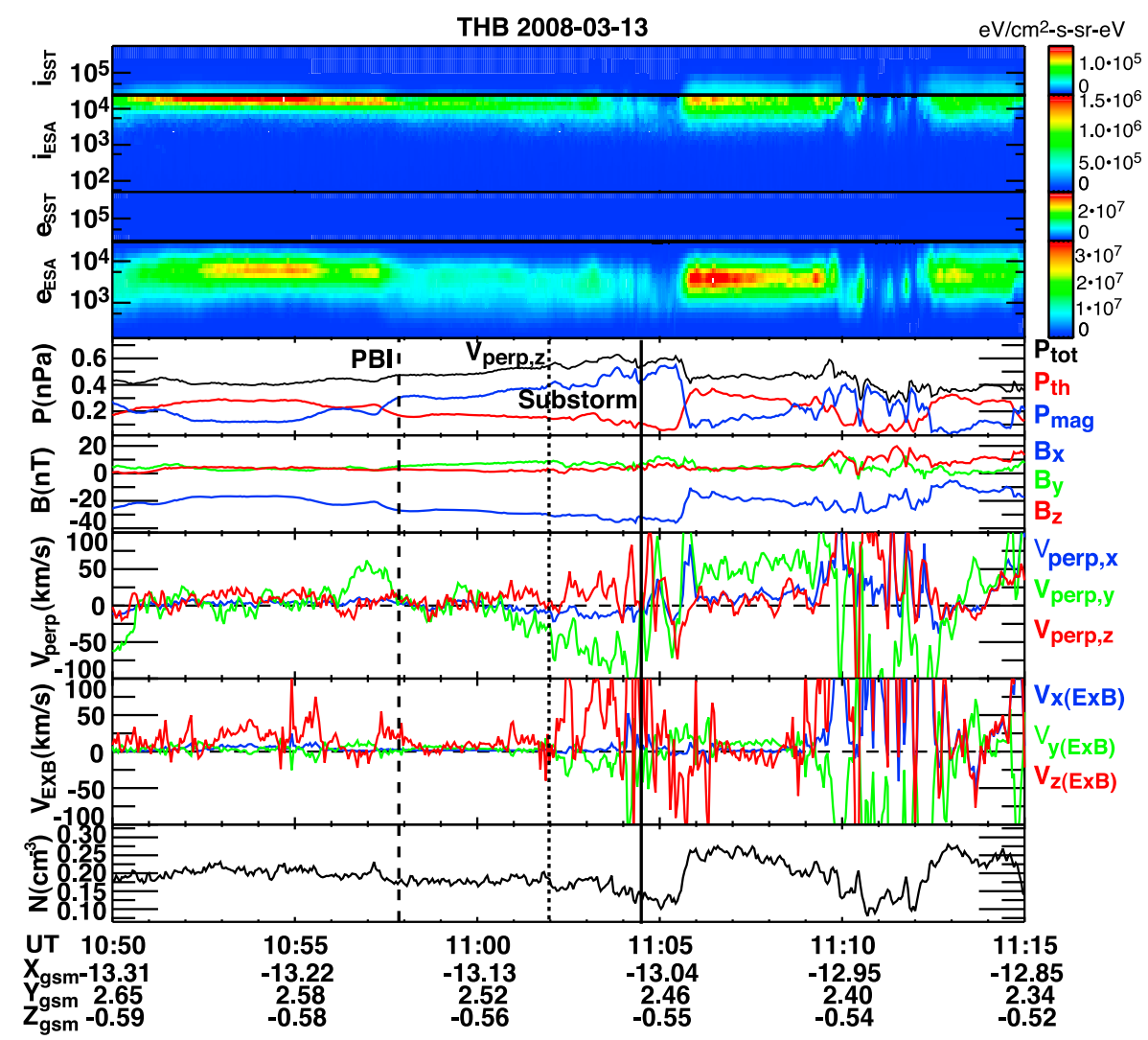

Figure 7a. Same as Figure 3 except for observations from THB during the period of the substorm on 13 March 2008.

the meridian scan and ground magnetometer data in Figure 1c. This was another high solar wind speed period, but there was persistent southward IMF starting $\sim 18$ min prior to the onset, leading to equatorward moving growth phase aurora seen in the ASI meridional scan and a ground magnetometer response.

[17] Both THB and THC were located near the outer boundary of the plasma sheet for this event, THB at $\mathrm{X} \sim$ $-13 \mathrm{R}_{\mathrm{E}}$ and THC $\mathrm{X} \sim-11 \mathrm{R}_{\mathrm{E}}$, observations from these spacecraft being shown in Figures $7 \mathrm{a}$ and $7 \mathrm{~b}$, respectively. While these spacecraft were only $\sim 0.5 \mathrm{R}_{\mathrm{E}}$ apart in $\mathrm{y}$, THB saw a preonset flow enhancement ( $\sim 2.5 \mathrm{~min}$ before onset) in the perpendicular flow and $\mathbf{E} \times \mathbf{B}$ component directed toward the center of the plasma sheet, but a persistent preonset flow enhancement was not observed on THC. This reflects the limited azimuthal width of such flow enhancements as might be expected from the longitudinally narrow $\mathrm{N}-\mathrm{S}$ arc, though it does not directly give a value for the flow channel width.

[18] Particle distribution functions $f$ are available during the time of the flow enhancement observed at THB, which allows us to check if the flowing distributions have the characteristics of particle transport due to the electric field drift that is expected to give the enhanced flows across the separatrix associated with enhanced reconnection. Distributions in the $y-z$ plane during one of the flow peaks during the preonset flow enhancement are shown in Figure 8 from both THB and THC. Shown over each distribution is a dotted circle centered at zero velocity with a radius of $\sim 700 \mathrm{~km} / \mathrm{s}$ and a solid curve along a constant $f$ contour near $700 \mathrm{~km} / \mathrm{s}$.
The THC $f$ contours are approximately circles centered on zero, as expected for a nondrifting isotropic distribution. On the other hand, the THB contours are approximately circular with center offset toward the positive $\mathrm{z}$ and negative $\mathrm{y}$ directions, which is the observed flow direction and is as expected from the electric field drift. These distributions support our interpretation that the observed flows toward the center of the plasma sheet are indeed due to electric field enhancements.

\subsection{Event Summary}

[19] Table 1 lists all of the events included in this study. Preonset enhancements in the perpendicular flow directed toward the center of the plasma sheet were seen for 11 of the 13 events, 2 spacecraft seeing the flow for 2 events. The flows initiated at the spacecraft location on average $3 \mathrm{~min}$ before onset, whereas the PBI, detected within the field of view of the available ASIs for eight events, initiated on average 5 min prior to onset (essentially the same as found by Nishimura et al. [2010] from a very much larger number of events). The flows were detected over essentially the entire range of available radial spacecraft locations, which was from $X=-11$ to $-26 R_{E}$.

\section{Summary and Conclusions}

[20] The present results offer a possible convergence of the inference from ASI observations of Nishimura et al. [2010] that new plasma crosses the polar cap boundary 


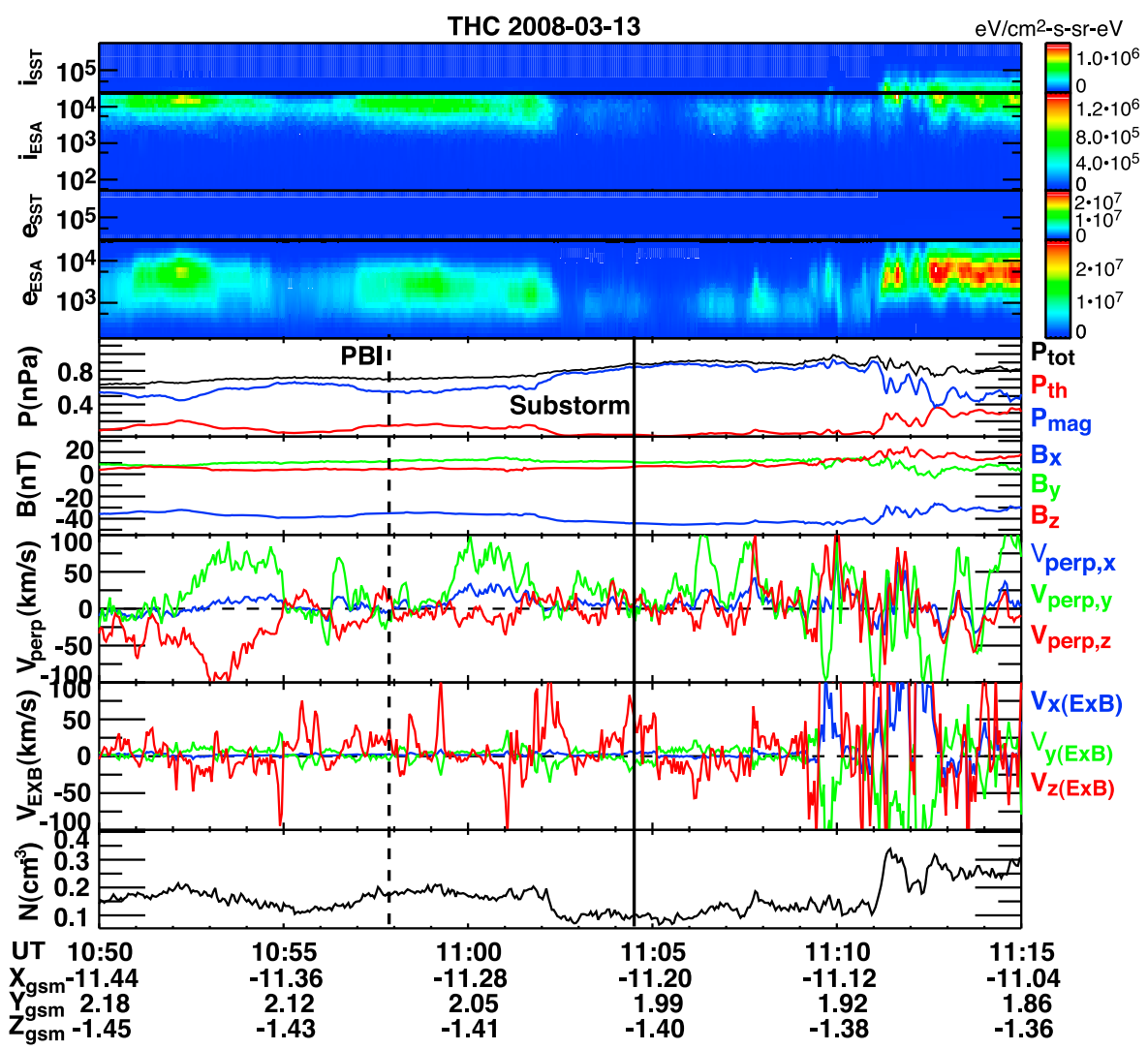

Figure 7b. Same as Figure 3 except for observations from THC during the period of the substorm on 13 March 2008.
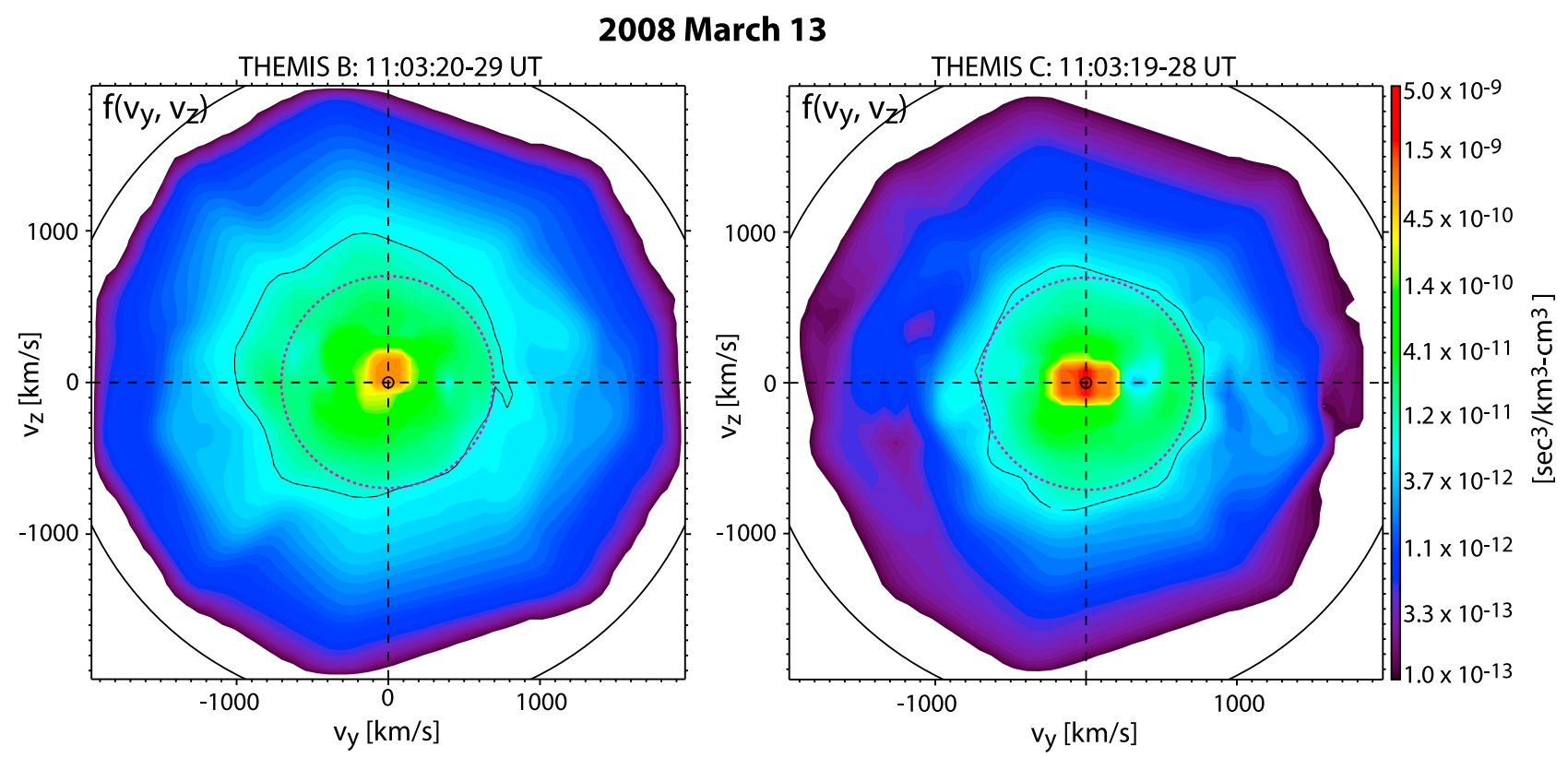

Figure 8. Ion distribution functions in the $y-z$ plane during one of the flow peaks of the preonset flow enhancement from THB and THC. Shown over each distribution is a dotted circle centered at zero velocity and a solid curve along a constant distribution function contour. 
Table 1. Summary of Events ${ }^{a}$

\begin{tabular}{|c|c|c|c|c|}
\hline Date & Onset & Spacecraft & PBI Time & $V_{\text {perp }, z}$ Time \\
\hline 1 Feb 2008 & 0953:36 & $B, X=-25.7$ & -11 & -6.5 \\
\hline 4 Feb 2008 & 0758:00 & $\mathrm{C}, \mathrm{X}=-18.8$ & -6.5 & -5 \\
\hline 4 Feb 2008 & 0837:24 & C, $X=-18.4$ & -2 & -1 \\
\hline 13 Feb 2008 & 1055:06 & $\begin{array}{l}\text { C, } X=-11.9 \\
\text { B, X }=-29.0\end{array}$ & -6 & $\begin{array}{l}-2.5 \\
\text { No }\end{array}$ \\
\hline 26 Feb 2008 & 0403:00 & $\begin{array}{l}B, X=-22.0 \\
C, X=-17.2\end{array}$ & ? & $\begin{array}{l}-5 \\
-3\end{array}$ \\
\hline 26 Feb 2008 & 0451:48 & $\begin{array}{l}B, X=-21.4 \\
C, X=-17.1\end{array}$ & ? & $\begin{array}{l}-1 \\
\text { No }\end{array}$ \\
\hline 1 Mar 2008 & 0339:12 & $\begin{array}{l}B, X=-21.7 \\
C, X=-17.0\end{array}$ & $?$ & $\begin{array}{l}-1 \\
-1\end{array}$ \\
\hline 5 Mar 2008 & 0603:54 & $\begin{array}{l}B, X=-19.3 \\
C, X=-15.7\end{array}$ & -2 & $\begin{array}{l}-3 \\
\text { No }\end{array}$ \\
\hline 13 Mar 2008 & 0609:42 & $B, X=-17.4$ & ? & -4 \\
\hline 13 Mar 2008 & $0724: 48$ & B, $X=-17.2$ & ? & No \\
\hline 13 Mar 2008 & 1104:24 & $\begin{array}{l}B, X=-13.1 \\
C, X=-11.1\end{array}$ & -7.5 & $\begin{array}{l}-2.5 \\
\text { No }\end{array}$ \\
\hline 15 Mar 2008 & 0417:12 & $\begin{array}{l}\mathrm{D}, \mathrm{X}=-11.1 \\
\mathrm{E}, \mathrm{X}=-11.1 \\
\mathrm{C}, \mathrm{X}=-18.5\end{array}$ & -4.5 & $\begin{array}{l}\text { No } \\
\text { No } \\
-2\end{array}$ \\
\hline 17 Mar 2008 & 0255:36 & $\begin{array}{l}\mathrm{C}, \mathrm{X}=-15.0 \\
\mathrm{~B}, \mathrm{X}=-18.5\end{array}$ & -3 & $\begin{array}{l}\text { No } \\
\text { No }\end{array}$ \\
\hline
\end{tabular}

${ }^{\mathrm{a}}$ From left to right, dates and UT of auroral onsets, spacecraft letter and $\mathrm{X}_{\mathrm{gsm}}$ location in $\mathrm{R}_{\mathrm{E}}, \mathrm{PBI}$ initiation time relative to the onset times in minutes, and initiation time of persistent $V_{\text {perp,z }}$ directed to the center of the plasma sheet relative to the onset times in minutes. In the PBI column, "?" indicates that there are not sufficient ASI observations available for PBI detection. In the $\mathrm{V}_{\text {perp,z }}$ column, "No" indicates that $\mathrm{V}_{\text {perp,z }}$ was not observed at least 0.5 min before onset.

into the plasma sheet and then intrudes to the near-Earth region of the plasma sheet, leading to substorm onset, and the interpretation of THEMIS observations at $\mathrm{X}=-17$ to $-22 R_{E}$ that enhanced tail reconnection precedes substorm onset. Using observations from the THEMIS spacecraft located near the outer boundary of the premidnight plasma sheet, we found enhanced perpendicular flows toward the center of the plasma sheet for 11 of 13 onset from $X=-11$ to $-26 \mathrm{R}_{\mathrm{E}}$. Also consistent with the above results are the enhanced ionospheric flows found by Lyons et al. [2010] to commonly enter the plasma sheet from the polar cap. The observations of Lyons et al. [2010] give evidence that the enhanced flows enter the plasma sheet from the polar cap, suggesting the possibility that the enhanced reconnection may be initiated from flows coming from outside the plasma sheet. Unlike with the radar observations from which the motion of the separatrix can often be estimated from motion of the poleward boundary of precipitation, the motion of the separatrix cannot be measured with spacecraft. Thus the interpretation that preonset flows measured by the spacecraft correspond to an enhancement of plasma transport across the separatrix requires the assumption that separatrix moves slower than the measured enhanced flows. We note that the observed PBIs did not abruptly change their motion when the spacecraft started to detect enhanced flows, indicating that the flow enhancement does not represent boundary motion.

[21] These observations present consistent evidence that enhanced flows bring plasma across the entire length of the tail field lines on the open-closed field line boundary, which is a signature of enhanced reconnection prior to substorm onset. The flows are not always seen by spacecraft located near the outer boundary, nor are they always seen within the ionosphere. This is not unexpected due to the localization of the enhanced flow in longitude, the flows being bounded in longitude by PBIs and N-S aurora to the west and downward field-aligned currents to the east. Consistent with this localization, enhanced flows toward the plasma sheet center were not observed on all spacecraft for five events where there were more than one spacecraft near the plasma sheet boundary.

[22] The time of the initiation of the observed flow enhancements on the spacecraft was typically a few minutes after detection of the PBIs on the ground, which is as expected from there being some time delay between when the flows first crossed the open-closed field line boundary and when they reached the spacecraft location and from the longitudinal localization and motion of the flow enhancements. Another possibility that might lead to a time delay between the ionospheric and magnetospheric initiation of the flows could be that electric field enhancements producing the flows propagate up along field lines from the polar cap ionosphere. It is known that ionospheric convection responds to IMF changes far more rapidly on the nightside than can be explained by solar wind propagation [Ridley et al., 1998; Ruohoniemi and Greenwald, 1998], which may be a result of the incompressibility of the ionosphere. This could lead to electric field changes propagating up field lines from the ionosphere on the nightside, which perhaps could also apply to more localized flow enhancements.

[23] It is important to note that there are many auroral PBIs and $\mathrm{N}-\mathrm{S}$ auroras, which are likely associated with localized enhanced reconnection at the plasma sheet boundary and enhanced flows within the plasma sheet. However, only very few of these flows lead to substorms. The ASI observations of Nishimura et al. [2010] suggest that substorm onset occurs via instability in the near-Earth plasma sheet that develops when flows that cross the plasma sheet outer boundary reach the substorm onset location within the inner plasma sheet. Thus much more than just the enhanced flow across the plasma sheet boundary is required to set off a substorm onset. The pressure distribution within the inner plasma sheet, the characteristics of the plasma carried by the enhanced flows, and the location to which this plasma is carried by the flows may all contribute to the fate and effects of the enhanced flows within the inner magnetosphere.

[24] Acknowledgments. This work at UCLA was supported by National Science Foundation grants ATM-0639312 and ATM-0646233 and NASA grant NNX09AI06G, and work at UCLA and Berkeley was supported by NASA contract NAS5-02099. We thank S. Mende and E. Donovan for use of the ASI data and the CSA for logistical support in fielding and data retrieval from the GBO stations. Financial support for the work of the FGM Lead Investigator Team at the Technical University of Braunschweig by the German Ministerium für Wirtschaft und Technologie and the Deutsches Zentrum für Luft- und Raumfahrt under grant $50 \mathrm{QP} 0402$ is acknowledged. The Alaskan magnetometer data used here were obtained from magnetometers operated by the Geophysical Institute of the University of Alaska, Fairbanks, and we thank NASA for supplying the time-shifted solar wind data.

[25] Robert Lysak thanks the reviewers for their assistance in evaluating this paper. 


\section{References}

Angelopoulos, V., et al. (2008), Tail reconnection triggering substorm onset, Science, 321, 931, doi:10.1126/science.1160495.

Angelopoulos, V., et al. (2009), Response to comment on "Tail reconnection triggering substorm onset," Science, 324, 1391, doi:10.1126/science. 1168045.

Auster, H. U., et al. (2008), The THEMIS fluxgate magnetometer, Space Sci. Rev., 141, 235, doi:10.1007/s11214-008-9365-9.

Blanchard, G. T., L. R. Lyons, O. de la Beaujardière, R. A. Doe, and M. Mendillo (1996), Measurement of the magnetotail reconnection rate, J. Geophys. Res., 101, 15,265, doi:10.1029/96JA00414.

Cowley, S. W. H., and W. J. Hughes (1983), Observation of an IMF sector effect in the y magnetic field component at geosynchronous orbit, Planet. Space Sci., 31, 73, doi:10.1016/0032-0633(83)90032-6.

de la Beaujardière, O., L. R. Lyons, and E. Friis-Christensen (1991), Sondrestrom radar measurements of the reconnection electric field J. Geophys. Res., 96, 13,907, doi:10.1029/91JA01174.

de la Beaujardière, O., L. R. Lyons, J. M. Ruohonmiemi, E. Friis-Christensen, C. Danielsen, F. J. Rich, and P. T. Newell (1994), Quiet-time intensification along the poleward auroral boundary near midnight, J. Geophys. Res., 99, 287, doi:10.1029/93JA01947.

Henderson, M. G., L. Kepko, H. E. Spence, M. Connors, J. B. Sigwarth L. A. Frank, H. J. Singer, and K. Yumoto (2002), The evolution of northsouth aligned auroral forms into auroral torch structures: The generation of omega bands and Ps6 pulsations via flow bursts, paper presented at the Sixth International Conference on Substorms, Univ. of Wash., Seattle, Wash.

Kim, H.-J., L. R. Lyons, S. Zou, A. Boudouridis, D.-Y. Lee, C. Heinselman, and M. McCready (2009), Evidence that solar wind fluctuations substantially affect the strength of dayside ionospheric convection, J. Geophys. Res., 114, A11305, doi:10.1029/2009JA014280.

Lyons, L. R., T. Nagai, G. T. Blanchard, J. C. Samson, T. Yamamoto, T. Mukai, A. Nishida, and S. Kokobun (1999), Association between Geotail plasma flows and auroral poleward boundary intensifications observed by CANOPUS photometers, J. Geophys. Res., 104, 4485, doi:10.1029/1998JA900140.

Lyons, L. R., et al. (2009), Evidence that solar wind fluctuations substantially affect global convection and substorm occurrence, J. Geophys. Res., 114, A11306, doi:10.1029/2009JA014281.

Lyons, L. R., Y. Nishimura, Y. Shi, S. Zou, H.-J. Kim, V. Angelopoulos, C. Heinselman, M. J. Nicolls, and K.-H. Fornacon (2010), Substorm triggering by new plasma intrusion: Incoherent-scatter radar observations, J. Geophys. Res., 115, A07223, doi:10.1029/2009JA015168.

McFadden, J. P., et al. (2008), The THEMIS ESA plasma instrument and in-flight calibration, Space Sci. Rev., 141, 277, doi:10.1007/s11214008-9440-2.

Mende, S. B., S. E. Harris, H. U. Frey, V. Angelopoulos, C. T. Russell, E. Donovan, B. Jackel, M. Greffen, and L. M. Peticolas (2008), The THEMIS array of ground-based observatories for the study of auroral substorms, Space Sci. Rev., 141, 357, doi:10.1007/s11214-008-9380-x.

Nakamura, R., W. Baumjohann, R. Schödel, M. Brittnacher, V. A. Sergeev, M. Kubyshkina, T. Mukai, and K. Liou (2001), Earthward flow bursts, auroral streamers, and small expansions, J. Geophys. Res., 106, 10,791, doi:10.1029/2000JA000306.
Nishimura, Y., L. Lyons, S. Zou, V. Angelopoulos, and S. Mende (2010), Substorm triggering by new plasma intrusion: THEMIS all-sky imager observations, J. Geophys. Res., 115, A07222, doi:10.1029/2009JA015166.

Ridley, A. J., G. Lu, C. R. Clauer, and V. O. Papitashvili (1998), A statistical study of the ionospheric convection response to changing interplanetary magnetic field conditions using the assimilative mapping of ionospheric electrodynamics technique, J. Geophys. Res., 103, 4023, doi:10.1029/97JA03328.

Ruohoniemi, J. M., and R. A. Greenwald (1998), The response of highlatitude convection to a sudden southward IMF turning, Geophys. Res. Lett., 25, 2913, doi:10.1029/98GL02212.

Sergeev, V. A., K. Liou, C.-I. Meng, P. T. Newell, M. Brittnacher, G. Parks, and G. D. Reeves (1999), Development of auroral streamers in association with localized impulsive injections to the inner magnetotail, Geophys. Res. Lett., 26, 417, doi:10.1029/1998GL900311.

Sergeev, V. A., et al. (2000), Multiple-spacecraft observation of a narrow transient plasma jet in the Earth's plasma sheet, Geophys. Res. Lett., 27, 851, doi:10.1029/1999GL010729.

Sibeck, D. G., and V. Angelopoulos (2008), THEMIS science objectives and mission phases, Space Sci. Rev., 141, 35, doi:10.1007/s11214-0089393-5.

Tsyganenko, N. A. (1995), Modeling the Earth's magnetospheric magnetic field confined within a realistic magnetopause, J. Geophys. Res., 100 5599, doi:10.1029/94JA03193.

Vasyliunas, V. M. (1984), Steady state aspects of magnetic field line merging, in Magnetic Reconnection in Space and Laboratory, Geophys. Monogr. Ser, vol. 30, edited by E. W. Hones, Jr., pp. 25-31, AGU, Washington, D. C

Zesta, E., E. Donovan, L. Lyons, G. Enno, J. S. Murphree, and L. Cogger (2002), Two-dimensional structure of auroral poleward boundary intensifications, J. Geophys. Res., 107(A11), 1350, doi:10.1029/2001JA000260.

Zou, S., L. R. Lyons, M. J. Nicolls, C. J. Heinselman, and S. B. Mende (2009), Nightside ionospheric electrodynamics associated with substorms: PFISR and THEMIS ASI observations, J. Geophys. Res., 114, A12301, doi:10.1029/2009JA014259.

V. Angelopoulos and A. Runov, Department of Earth and Space Sciences, 3845 Slichter Hall, University of California, Los Angeles, CA 90095-1567, USA.

K.-H. Fornacon, Institut für Geophysik und Extraterrestrische Physik, Technische Universität Braunschweig, Mendelssohnstrasse 3, D-38106 Braunschweig, Germany.

D. Larson, J. McFadden, and S. Mende, Space Sciences Laboratory, University of California, Berkeley, 7 Gauss Way, Berkeley, CA 947207450, USA.

L. R. Lyons, Y. Nishimura, and X. Xing, Department of Atmospheric and Oceanic Sciences, University of California, 405 Hilgard Ave., 7127 Math Sciences Bldg., Los Angeles, CA 90095-1565, USA. (larry@ atmos.ucla.edu)

S. Zou, Department of Atmospheric, Oceanic and Space Sciences, University of Michigan, 2455 Hayward St., Ann Arbor, MI 48109, USA. 